\title{
The Effect of Counterfactual Thinking on the Sunk Cost Effect
}

\author{
YANG Fan-yu \\ National Taiwan Normal University (NTNU), Taipei, Taiwan
}

\begin{abstract}
Counterfactual thinking is helpful to comprehend the mistakes made previously and to move toward by proposing future actions to facilitate the success of self-regulation. The sunk cost effect rationalizes a strategy, which is the aim of studies on decision-making. However, few of them have discussed the influence of counterfactual thinking to the sunk cost effect. This study assumes that downward counterfactual thinking can regulate the unhappy mood at the moment for relief, which may reduce the sunk cost fallacy; upward counterfactual thinking, on the contrary, emphasizes the improvement of future behaviors, which may increase the sunk cost fallacy.
\end{abstract}

Keywords: counterfactual thinking, sunk cost effect, self-regulation

\section{Introduction}

Counterfactual thinking (CT) is the process in which people create alternative outcomes to negative events that have already occurred. For example, an individual that was robbed of his wallet in the subway may produce counterfactuals post facto, such as "What if I hadn't entered this crowded carriage?" "If I had only secured the inside pocket of my jacket!", or "If I had been more attentive to the people around me, things may have been different". This mental creation of alternative outcomes is known as CT. People employ CT to create hypothetical scripts to change a single or numerous prior events (Catellani, Alberici, \& Milesi, 2004).

CT is generally triggered when people wish to predict or control future events (Roese \& Olson, 1995). When contemplating past events, CT enables us to mentally control past behaviors and create more favorable or unfavorable alternatives. CT does not simply focus on past failures; rather, it is an associative thinking process that links past mistakes and future opportunities, thereby increasing one's chances of self-regulatory success and functionalizing CT. Functional CT involves a set of situations where one can reflect on past events and imagine future possibilities. A key aspect of a CT's functionality is that insight about past mistakes is converted into plans for future action, thereby improving self-regulatory success (Smallman \& McCulloch, 2012). It is therefore apparent that $\mathrm{CT}$ is a type of psychological mechanism for self-regulation.

\section{Counterfactual Thinking}

Miller, Markman, Wagner, and Hunt (2013) found that CT decreases discrimination. In the present study, undergraduate subjects were instructed to complete the Attitude Towards Gay (ATG) Men Scale to test their gender discrimination attitude and to establish a baseline for their attitudes towards gay men. The subjects were then randomly allocated into a control group and an experimental group. Subjects in the experimental group were instructed to imagine a situation where they were having a pleasant conversation with a gay man. The gay man informs them that he had recently received a bag of hate mail against his sexual orientation. The subjects

YANG Fan-yu, Ph.D. Student, Department of Educational Psychology and Counseling, National Taiwan Normal University (NTNU), Taipei, Taiwan. 
were then instructed to think of an alternative in which the sexual discrimination event did not occur and list all their views on the non-occurrence of the event. By contrast, the subjects in the control group were instructed to image a natural scene and list the objects they observe in the scene. Following the completion of the aforementioned test, the subjects were instructed to complete the second-round ATG Scale, as well as the Internal Motivation Scale (IMS) and the External Motivation Scale (EMS) to test their non-discrimination internal and external motivations. Findings indicated that the gender biases of the subjects in the experimental group significantly dropped. This study verified that CT mediated negative attitudes and even mitigated students' discrimination against homosexuals.

$\mathrm{CT}$ is directional. Downward CT is when people imagine a worse alternative, and the more common upward CT is when people imagine a better outcome to negative events (Fraser, 2001). Alternatives produced through upward CT are typically more favorable than the factual outcome of an event. By imagining upward counterfactuals, individuals are able to identify methods to improve future outcomes. Therefore, upward CT is associated with the preparative function. By contrast, alternatives produced through downward CT are typically less favorable than the factual outcome of an event. The narration formed through this type of thinking includes "What ifs..." Thus, downward CT is correlated to the affective function (Markman, Gavanski, Sherman, \& McMullen, 1993).

Yoon and Vargas (2010) indicated that when individuals assume that upward counterfactuals are more likely to occur, they typically deem the factual outcome of an event to be less favorable. By contrast, when individuals assume that downward counterfactuals are more likely to occur, they typically deem the factual outcome of an event to be more favorable. Customers with upward CT may think, "If this store were to offer more discounts, I would save more money", while those with downward CT may think, "If this store were to offer less discounts, I would spend more money". Roese (1994) asserted that people strategically employ downward CT to make themselves feel better and upward CT to improve future performance. When people expect to encounter a similar task in the near future, they carefully employ upward CT to prepare for the future, even if the original task was concluded positively. Thus, the effects of $\mathrm{CT}$ are seemingly beneficial when upward CT and downward CT are employed interchangeably (Roese, 1997).

Roese and Olson (1995) proposed that CT has two major purposes: (1) to help people learn from their mistakes and (2) to make people feel better when situations may become worse. Subsequently, the primary function of $\mathrm{CT}$ is the influence it has on specific emotions, such as regret, relief, and disappointment. The emotions are collectively called counterfactual-thinking-based emotions, or CTEs, because they include those that compare factual situations to counterfactual situations. Upward CT occurs when counterfactual situations are more favorable than the factual situation. This mode of thinking generates regret. By contrast, downward CT occurs when counterfactual situations are less favorable than the factual situation. This mode of thinking generates relief (Kasimatis \& Wells, 1995).

The aforementioned discussion shows that upward CT and downward CT occur in different situations. Upward CT typically generates negative emotions, such as regret, because individuals imagine more favorable counterfactual outcomes than the factual outcome, consequently motivating them to take action to improve the current situation. By contrast, downward CT generates positive emotions, such as relief, because individuals imagine less favorable counterfactual outcomes than the factual outcome, consequently hindering them from taking additional action to improve the current situation. 


\section{Sunk Cost and Decision-Making}

Sunk cost (SC) refers to costs that have already been incurred. They neither influence future costs, nor change due to present or future actions (Hilton, 2005). People show a greater tendency to continue an endeavor once an investment has been made. This situation is called the "sunk cost effect" (Arkes \& Blumer, 1985).

Arkes and Blumer (1985) divided customers into three groups. The first group of customers spent $\$ 15$ on tickets, the second group spent $\$ 13$, and the third group spent $\$ 8$. Findings showed that the customers who bought discounted tickets attended fewer performances than those who bought their tickets for the normal price of $\$ 15$. Ticket price should have no influence on performance attendance, because payments that have incurred cannot be recovered. However, the findings clearly indicated otherwise. This study argued that the reason for the SC effect originates from people's desire not to appear to be wasteful. The following example was a problem proposed by Arkes and Blumer (1985): "Assume that you have spent $\$ 100$ on a ticket for a weekend ski trip to Michigan. Several weeks later, you buy a $\$ 50$ ticket for a weekend ski trip to Wisconsin. You think you will enjoy the Wisconsin ski trip more than the Michigan ski trip. As you are putting your just-purchased Wisconsin ski trip ticket in your wallet, you notice that the Michigan ski trip and the Wisconsin ski trip are for the same weekend! It's too late to sell either ticket, and you cannot return either one. You must use one ticket and not the other. Which ski trip will you go on?"

The findings showed that the majority of the subjects chose to take the less-enjoyable trip to Michigan. A number of the subjects chose to take the less-favorable trip, because they believed that they would lose twice the money if they took the cheaper trip to Wisconsin (Arkes \& Blumer, 1985). These results clearly denoted SC Arkes and Ayton (1999) later asserted that explanations for wastefulness received the greatest attention. The overgeneralization of "don't waste" is responsible for the SC effect, which is manifested in the subjects' failure to heed cost-benefit considerations - that is, reinforcement contingencies. Individuals should focus decision-making on enhancing the positive aspects of spending and engagements rather than being concerned with resources that have already been incurred.

A previous study argued that the sunk-cost fallacy (SCF) changes with age. The development of children's and teenagers' abilities corresponds to their cognitive mechanics. Subsequently, cognitive mechanics are more influential in childhood and adolescence and become less central in adulthood due to increases in automaticity and cognitive pragmatics. In later adulthood, temporal horizons that focus on the "here and now", coupled with a motivation to maintain positive emotion, may contribute to further decreases in future SCF. The motivation to maximize positive emotion in the "here and now" may decrease rumination about past losses and direct attention to rewarding alternatives in the present. By contrast, temporal horizons that focus on the future may be associated with increases in the SCF, but only when positive consequences of persistence are anticipated (Strough, Karns, \& Schlosnagle, 2011).

According to the aforementioned discussion, SCF could be reduced by focusing on the present. Therefore, this study hypothesized that downward CT primarily functions as a mediator for alleviating unpleasant emotions, thereby generating relief and reducing SCF. This study also hypothesized that upward CT focuses on improving future performance, which may increase SCF. Reducing the SC effect to increase the rationality of decisions has been a long-standing objective of many studies relating to decision-making. However, few studies have investigated the influences of CT on the SC effect.

In summary, the following hypotheses are proposed in the present study: (1) upward CT increases the SC 
effect of the participants; and (2) downward CT reduces the SC effect of the participants.

\section{Methodology}

\section{Research Subjects}

The research participants comprised 120 students attending a vocational school in Taoyuan County, Taiwan. The participants were aged between 17 and 20. Among the participants, 70 were male and 50 were female. They were randomly allocated into six groups.

\section{Research Design}

This study adopted a $2 \times 3$ two-factor between-subject research design. The independent variables comprised CT and SC. CT was further characterized into upward CT and downward CT, and SC was characterized into high SC, moderate SC, and low SC. The dependent variable was the willingness to continue studying or learning.

\section{Research Tools}

This study developed an imagination task as the research tool. Instructions were printed on the worksheet. Instructions for the participants in the high SC groups were as follows: "Imagine the following situation: You are not interested in the course you are studying at vocational school and you do not want to study this course. You encounter many difficulties in learning, obtain poor grades, and feel demotivated during class. You have been in this course for a year since admission". Similar instructions were provided to the participants in the moderate SC groups with the exception of study time, which was reduced to six month: "Imagine the following situation: You are not interested in the course you are studying at vocational school and you do not want to study this course. You encounter many difficulties in learning, obtain poor grades, and feel demotivated during class. You have been in this course for six months since admission". Instructions for the participants in the low SC groups were as follows: "Imagine that you are enrolled in a creative arts course, such as music or drawing. The course comprises eight classes over eight weeks. After attending three classes, you find that you do not enjoy the course and the course is dull". After reading the instructions, participants in the upward CT groups were provided with the following sentence: "Currently, this course seems boring, but you may gradually become interested. You may____ in future learning and feel . (Complete the sentence)". Participants in the downward CT groups were provided with the following sentence: "Currently, this course seems boring, and continuing with the course is a waste of time. You may in future learning and feel (Complete the sentence)". Finally, the participants were instructed to complete questionnaire to measure their willingness to continue studying or learning (hereafter referred to as "willingness"). They were scored on a scale of 1 to 9 , where 1 represented "definite discontinuation" and 9 represented "definitely continuation".

\section{Experiment Procedures}

The research participants were randomly allocated into six groups. The groups were provided with different hypothetical scripts. Participants in the high and moderate SC groups were provided with a situation concerning the length of time in which they attended a course in vocational school (e.g., cosmetics and hairdressing or information processing). Subsequently, the participants were not interested with the course and encountered many difficulties in learning. By contrast, the participants in the low SC groups were provided with a situation in which they attended an eight-week creative arts course. However, they found the course to be dull after attending three classes. Based on their experimental groups, the participants then engaged in CT 
and completed a sentence relating the counterfactual situation. Finally, the participants completed a 9-point willingness questionnaire, where 1 represented "definite discontinuation" and 9 represented "definitely continuation".

\section{Results}

The mean and standard deviation results were as follows: Participants in high SC groups obtained $\mathrm{M}=$ 6.15, $\mathrm{SD}=1.76$ for upward $\mathrm{CT}$ and $\mathrm{M}=4.60, \mathrm{SD}=1.93$ for downward $\mathrm{CT}$. Participants in the moderate $\mathrm{SC}$ groups obtained $\mathrm{M}=5.00, \mathrm{SD}=1.89$ for upward $\mathrm{CT}$ and $\mathrm{M}=3.80, \mathrm{SD}=2.21$ for downward $\mathrm{CT}$. Participants in the low $\mathrm{SC}$ groups obtained $\mathrm{M}=4.75, \mathrm{SD}=1.86$ for upward $\mathrm{CT}$ and $\mathrm{M}=3.50, \mathrm{SD}=2.46$ for downward $\mathrm{CT}$.

The two-factor ANOVA results were as follows: The primary effect of SC on willingness achieved significance $(\mathrm{F}(2,114)=4.18 ; \mathrm{p}<0.05)$. A Bonferroni post-hoc test indicated differences in the high and low SC groups, where willingness in the high SC groups was higher than that of the low SC groups. Subsequently, willingness between the high and moderate SC groups, and that between the moderate and low SC groups, failed to achieve significant differences. The primary effect of $\mathrm{CT}$ on willingness also achieved significance (F $(1,114)=12.90 ; \mathrm{p}<0.001)$. Willingness in the upward CT groups was higher than that in the downward CT groups. However, the interaction between $\mathrm{CT}$ and SC failed to achieve significance $(\mathrm{F}(2,114)=.087 ; \mathrm{p}=$ 0.917). The results are shown in the following figure.

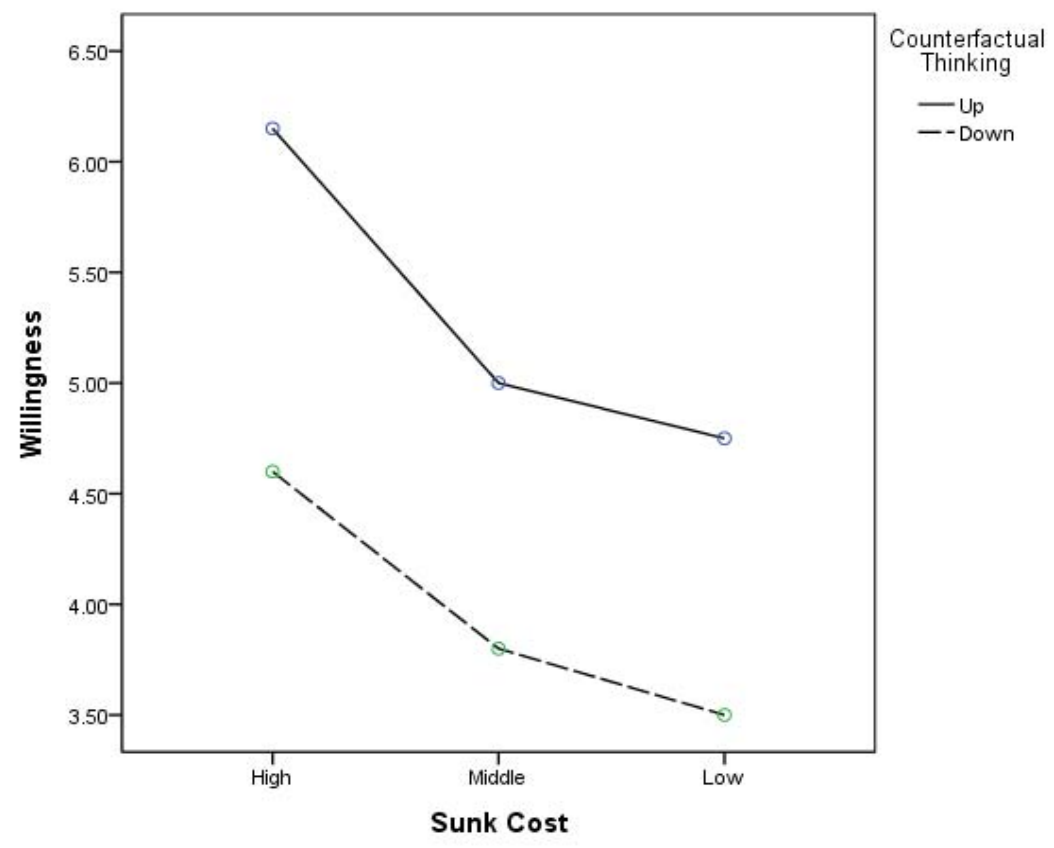

Figure 1. The interaction of sunk cost and counterfactual thinking.

\section{Discussion}

The present study focuses on the influences that CT has on willingness. In the present study, students who underperform as a result of continuing to study in courses or attend creative arts courses that do not interest them generally continue to invest sunk time and money. This study hypothesized that upward CT increases sunk cost, whereas downward CT reduces sunk cost. The results obtained in the present study supported the 
proposed hypotheses. Findings indicated that upward CT participants demonstrated increased willingness than downward CT participants. Figure 1 revealed in the 9-point scale that downward CT groups scored a mean value of less than 5, regardless of the high, moderate, or low SC groups. These results suggest that the upward CT participants may have generated favorable outcomes for continuing to study or desired to improve future performance. Therefore, the participants decided to continue studying, increasing their SCF (Strough et al., 2011). By contrast, downward CT improved the participants' emotions, enabling them to shift their focus from improving future performance and consequently reducing SC. This situation was most apparent in the downward CT, low SC group, where six of the participants selected Option 1 (definite discontinuation). This number of participants who selected Option 1 in the downward CT, low SC group was far greater than those in any other group.

The findings of the present study showed that different levels of SC impose varying degrees of influence on participants' willingness. These results suggest that situations with high SC increase participants' willingness. By contrast, participants are less willing to continue studying uninteresting courses in moderate SC situations and demonstrate the least willingness to continue studying uninteresting courses in low SC situations. Although post-hoc comparisons only revealed a significant difference between the high and low SC groups, the mean values obtained in the present study confirmed that the amount of SC invested by participants influences their decision on continuing to study and attend uninteresting courses. These results are consistent with those proposed by Arkes and Blumer (1985), who indicated that participants' decisions are influenced by the amount of SC they invest, and high SC investments stimulate participants to select options they are uninterested in.

The interaction between $\mathrm{CT}$ and SC failed to achieve significance. The findings of the present study indicated that upward CT increased participants' willingness. In other words, upward CT increased SC. Only the low SC group scored a mean value of less than 5 for the 9-point questionnaire (4.75). By contrast, downward CT reduced participants' willingness in all three SC groups. In other words, downward CT reduces SC.

\section{Conclusion and Suggestions}

This study found that $\mathrm{CT}$ influences the investment of SC, whereas upward CT may stimulate people to increase SC investments. Upward CT participants exhibited increased willingness even when they were underperforming as a result of continuing to study in courses or attending creative arts courses that do not interest them. By contrast, downward CT may reduce investment in SC, preventing participants from continuing to invest time and money, wasting time on uninteresting courses, or continuing ineffective learning. Downward CT may change participants' initial decisions or even stipulate them to withdraw from continued study. This study suggested that such findings hold considerable academic value. A previous study indicated that engaging in upward CT prevents people from making mistakes and aids them in focusing on improving future performance (Roese, 1997), which is a positive function of upward CT. However, this study found that such a positive function of upward CT also stimulates people to continue investing in SC, resulting in them wasting unnecessary time and resources. These results were consistent with the findings of Strough et al. (2011), who argued that when predictions show continuous, positive outcomes, increased SCF is associated with people's focus on the future. Although downward CT generates less favorable counterfactual situations than the factual outcome, this study found that downward CT had a positive effect on reducing SC, possibly because downward CT promotes positive emotions (Roese, 1994). Downward CT stimulates people to focus on the 
present and reduces their continued investment in SC, thereby enhancing their ability to remain positive. These results are consistent with those proposed by Strough et al. (2011), who asserted that maintaining positive emotional motivations might benefit the future reduction of SCF.

The results of the present study are meaningful to academic research, because studies relating to the application of CT in education are scarce. Leung, Hou, Gati, and Li (2011) examined the effects of parental expectations and cultural-values' orientation on career decision-making difficulties. In the high schools and vocational schools of Taiwan, the courses that many students are studying may be inconsistent with their aptitude. In actuality, Taiwanese students consider not only personal interest and social development expectation when choosing future career development, but also parents' expectations. Subsequently, students may encounter learning difficulties stemming from an increasing lack of interest and fall into a dilemma. If student are able to disregard already-expended energy and effort, decisively withdraw from the uninteresting course, and enroll in a course that is consistent with their specialization and interests, then they may demonstrate better development and performance and make better use of their talents. For students that remain attached to their already-invested SC, downward CT may help them change their views and promote better career development. As far as designing a CT model and applying it into the career counseling of students, this problem remains open for further discussion.

\section{Limitations}

Research subjects only comprised 120 students from a vocational school in Taoyuan, Taiwan. Whether these participants can appropriately represent the majority of Taiwanese high school and vocational school students and whether examining other students also yields similar results remain to be verified in subsequent research.

This study also did not measure the validity and reliability of the research tools, as is customary with previous experimental research. Confirming the reliability and validity of the research tools may enhance research comprehensiveness.

Only one experiment was conducted in the present study. Although the results complied with expectations, this study was unable to observe the participants' emotional conditions during the course of their decision-making process through the experiment procedures. Subsequently, this study was unable to determine the views and factors that influenced participants' decision for or against continued study when they were engaged in CT.

\section{Suggestions}

Findings of the present study indicated no interaction between CT and SC when they were applied on students' willingness to continue studying. Although this does not violate the proposed hypotheses, determining whether these factors interact with each has significant value. Moving forward, researchers can consider employing other verification processes to uncover other potential findings.

The researcher neither examined the decision process of the subjects engaging in $\mathrm{CT}$, nor identified the factors influencing their decision to continue or discontinue studying their course. In the future, researchers can develop a more comprehensive design to determine the views and emotions of research subjects during their decision-making processes to further verify the research findings.

If participants' decision models are determined prior to experimentation, then the influences that these 
models have on their decisions could be determined. Additionally, the interactions between different decision models and $\mathrm{CT} / \mathrm{SC}$ could be examined to increase research comprehensiveness.

Strough et al. (2011) asserted that SCF changes with age, and that the different cognitive development of teenagers and adults may produce different results. Thus, if the relationship between the CT processes and SC effects of people at various ages can be examined, then unexpected beneficial findings may be discovered.

\section{References}

Arkes, H. R., \& Ayton, P. (1999). The sunk cost and concorde effects: Are humans less rational than lower animals? Psychological Bulletin, 125, 591-600.

Arkes, H. R., \& Blumer, C. (1985). The psychology of sunk cost. Organizational Behavior and Human Decision Processes, 35, 124-140.

Catellani, P., Alberici, A., \& Milesi, P. (2004). Counterfactual thinking and stereotypes: The nonconformity effect. European Journal of Social Psychology, 34, 421-436.

Fraser, C. O. (2001). Was it my fault? Effects of counterfactual mutation focus and self-presentation strategy. Journal of Applied Social Psychology, 31(5), 1076-1095.

Hilton, R. (2005). Managerial accounting (6th ed.). Boston: McGraw-Hill Irwin.

Kasimatis, M., \& Wells, G. L. (1995). Individual differences in counterfactual thinking. In N. J. Roese and J. M. Olson (Eds.), What might have been: The social psychology of counterfactual thinking (pp. 81-101). Mahwah, NJ: Erlbaum.

Leung, S. A., Hou, Z. J., Gati, I., \& Li, X. (2011). Effects of parental expectations and cultural-values orientation on career decision-making difficulties of Chinese university students. Journal of Vocational Behavior, 78, 11-20.

Markman, K. D., Gavanski, I., Sherman, S. J., \& McMullen, M. N. (1993). The mental simulation of better and worse possible worlds. Journal of Experimental Social Psychology, 29, 87-109.

Miller, A. K., Markman, K. D., Wagner, M. M., \& Hunt, A. N. (2013). Mental simulation and sexual prejudice reduction: The debiasing role of counterfactual thinking. Journal of Applied Social Psychology, 43, 190-194.

Roese, N. J. (1994). The functional basis of counterfactual thinking. Journal of Personality and Social Psychology, 66, 805-818.

Roese, N. J. (1997). Counterfactual thinking. Journal of Personality and Social Psychology, 121, 133-148.

Roese, N. J., \& Olson, J. M. (1995). Counterfactual thinking: A critical overview. In N. J. Roese and J. M. Olson (Eds.), What might have been: The social psychology of counterfactual thinkin (pp. 1-55). Mahwah, NJ: Erlbaum.

Smallman, R., \& McCulloch, K. C. (2012). Learning from yesterday's mistakes to fix tomorrow's problems: When counterfactual thinking and psychological distance collide. European Journal of Social Psychology, 42, 383-390.

Strough, J., Karns, T. E., \& Schlosnagle, L. (2011). Decision-making heuristics and biases across the life span. Annals of the New York Academy of Sciences, 1235, 57-74.

Yoon, S., \& Vargas, P. T. (2010). Feeling happier when paying more: Dysfunctional counterfactual thinking in consumer affect. Psychology \& Marketing, 27(12), 1075-1100. 